\title{
La formación de los empleados públicos desde el punto de vista jurídico y organizacional. Dos perspectivas necesariamente entrelazadas
}

Rashid Mohamed Vázquez

DOI: https://doi.org/10.47623/ivap-rvap.109.2017.1.13

\begin{abstract}
Sumario: I. Introducción. - II. La formación desde un punto de vista jurídico. El derecho individual a la formación. El deber de formarse. Posibles consecuencias en casos de incumplimiento. La formación y su relación con el art. 103.1 CE. Formación e Igualdad.III. La formación desde el punto de vista organizacional. El carácter estratégico de la formación. La formación en competencias y la formación ética como complemento necesario de la formación técnica. Los cauces para la virtualidad de la formación: la formación presencial frente al e-learning y la formación activa frente a la formación pasiva.-IV. Reflexiones finales.-V. Bibliografía.
\end{abstract}

\section{Introducción}

El objeto de este trabajo es aportar un análisis sobre la formación de los empleados al servicio de las Administraciones Públicas desde dos perspectivas diferentes y no necesariamente antagónicas: la formación desde un punto de vista jurídico - como derecho y deber del empleadoy la formación desde una perspectiva organizacional -óptica basada en determinar el mejor modo de configurar la formación con arreglo a los objetivos de la propia organización-.

Ciertamente la formación puede concebirse desde una primera perspectiva jurídica como derecho y como deber de los empleados públicos. Procede desde ese punto de vista realizar un estudio jurídico de la formación de los empleados públicos del que se ocupará el epígrafe II de este trabajo.

Para ello, se partirá en primer lugar de la configuración jurídica como derecho individual que da a la formación el Estatuto Básico del Empleado Público - en adelante EBEP-. Posteriormente se pasará a remarcar que la formación es al mismo tiempo un deber de los empleados públicos, como se puede inferir de la propia regulación del EBEP. También se hará referencia a la obligatoriedad en la formación que para ciertos casos 
prevé el art. 10.1 de la Resolución de 28 de diciembre de 2012, de la Secretaría de Estado de Administraciones Públicas, una norma sobre la que se reflexionará con detalle, pues presenta algunos aspectos que podrían ser controvertidos. Tras ello, se profundizará en el análisis de las consecuencias jurídicas del incumplimiento de este deber de formarse y la posibilidad de acudir a la vía disciplinaria en el caso de un funcionario que no asista a un determinado curso formativo. Para finalizar el análisis jurídico de la formación del personal al servicio de las administraciones públicas, se reparará en la conexión entre la formación y el artículo 103.1 del texto constitucional, así como en la relación entre formación y el derecho fundamental a la igualdad reconocido en el art. $14 \mathrm{CE}$ y en otras normas que deberán tenerse en cuenta en esta materia.

Desde una segunda perspectiva, también puede hablarse de la formación como un instrumento de las organizaciones públicas para la planificación de recursos humanos dirigido a lograr la eficaz prestación de los servicios públicos con una eficiente utilización de recursos. Dentro de esta segunda línea de trabajo -epígrafe III-, nuestro estudio profundizará en el análisis de la formación desde el punto de vista organizacional, partiendo en primer lugar del carácter estratégico que reviste la formación de los empleados públicos. A continuación se incidirá en la importancia de que esta política de formación esté orientada al logro de competencias vinculadas a una gestión eficaz y eficiente - adaptación al entorno, trabajo en equipo, orientación a resultados, etc. - pero no solo eso, sino que también deberá centrarse en aspectos éticos como mejor garantía de la integridad del sector público. Finalmente se apuntarán algunas breves reflexiones sobre los cauces para la virtualidad de la formación, dónde se plantea una disyuntiva por un lado entre la formación presencial frente y el e-learning y por otro entre la formación activa frente a la formación pasiva.

\section{La formación desde un punto de vista jurídico. El derecho individual a la formación. El deber de formarse. Posibles consecuencias en casos de incumplimiento. La formación y su relación con el art. 103.1 CE. Formación e Igualdad}

La formación del personal al servicio de las administraciones públicas se configura en nuestro ordenamiento jurídico como un derecho individual de los empleados públicos. En concreto el artículo 14.g del Real Decreto Legislativo 5/2015, que aprueba el vigente texto refundido del Estatuto Básico del Empleado Público(1), señala: "Los empleados públicos tienen los si-

(1) Resulta oportuno tener presente que el EBEP se aprobó ya en 2007, mediante la ley 7/2007. 
guientes derechos de carácter individual en correspondencia con la naturaleza jurídica de su relación de servicio: (...) g) A la formación continua y a la actualización permanente de sus conocimientos y capacidades profesionales, preferentemente en horario laboral».

De esta forma la norma configura la formación en primer lugar como un derecho de todos los empleados públicos comprendidos en el campo de aplicación del EBEP que define su art. 2. Se trata por tanto de un derecho que corresponde, no solo al personal laboral - al que en realidad ya le sería de aplicación en todo caso conforme al ordenamiento laboral (2) - sino que gracias a este reconocimiento en el ordenamiento jurídico administrativo por el art. 14 EBEP, también constituye un derecho individual del personal funcionario. Ello tiene trascendencia si se considera la importancia relativa del personal funcionario dentro de la plantiIla de las Administraciones Públicas. Recordemos que la STC 99/1987, que declaraba nula la anterior redacción del art. 15 de la Ley 30/1984 - referido a los puestos que puede desempeñar el personal laboral-, ponía de manifiesto la existencia de un principio de preferencia constitucional a favor de los funcionarios públicos derivado de los arts. 103.3 y 149.1.18 CE, tratándose de una sentencia que configura un carácter de generalidad asociado al personal funcionario frente a una excepcionalidad propia del personal laboral(3). Ello explica la preponderancia del personal funcionario en la composición de la plantilla de la Administración Pública - de acuerdo con los datos del Registro Central de Personal al que se refiere el art. 71 del EBEP, más del 60\% del personal es funcionario de carrera (4)-.Por ello el reconocimiento en una norma de derecho administrativo con rango legal, de un derecho individual a la formación - no reconocido previamente en la Ley 30/1984- extensible a todos los tipos de empleados públicos con inclusión de los funcionarios, no es una cuestión baladí y configura un derecho subjetivo que puede ser exigible desde un punto de vista individual con independencia de que la relación del empleado con la Administración sea de carácter laboral o de carácter administrativo.

(2) El derecho individual a la formación se reconoce a los trabajadores por cuenta ajena en el artículo 4.2.b del RD Legislativo 2/2015 por el que se aprueba texto refundido del Estatuto de los Trabajadores. Cabe recordar que el art. 7 del EBEP se ocupa de la normativa aplicable al personal laboral, al que además de serle de aplicación los preceptos del propio EBEP que así lo dispongan, le son de aplicación las normas laborales.

(3) RIVERO LAMAS, Juan, «EI proceso de laboralización de la función pública: aspectos críticos y límites", en Anuario Jurídico de la Rioja, n. ${ }^{\circ}$ 2, 1996, págs. 15-20.

(4) El Boletín Estadístico del Registro Central de Personal recoge datos del personal al servicio de diferentes administraciones y está disponible en: http://www.sefp.minhafp.gob.es/dam/es/web/ publicaciones/centro_de_publicaciones_de_la_sgt/Periodicas/parrafo/Boletin_Estadis_Personal/ BEPSAP_2016_julio_CORREGIDO.PDF.PDF (última consulta 10 de Septiembre de 2017). 
Pero por otro lado, las necesidades de una organización de una magnitud tan considerable como es la Administración Pública - que como mandata el art. 103.1 de nuestra Constitución, debe servir de forma objetiva y eficaz los intereses generales, una idea en la que insistiremos más adelante- justifican que como contrapeso a la definición legal de la formación como un derecho individual de los empleados públicos, el EBEP la configure al mismo tiempo como un deber de estos empleados. En este sentido el art. 54.8 del EBEP dispone que los empleados públicos «mantendrán actualizada su formación y cualificación».

Relacionado con el deber de formarse resulta reseñable destacar lo establecido en el art. 10.1 de la Resolución de 28 de diciembre de 2012, de la Secretaría de Estado de Administraciones Públicas, por la que se dictan instrucciones sobre jornada y horarios de trabajo del personal al servicio de la Administración General del Estado y sus organismos públicos. El precepto señala que: "La Administración podrá determinar la asistencia obligatoria a aquellas actividades formativas necesarias para el buen desempeño de las tareas propias del puesto de trabajo, en cuyo caso su duración se considerará como tiempo de trabajo a todos los efectos". No obstante, en nuestra opinión resulta jurídicamente discutible que la Administración ejerza esta potestad con base en tal precepto - que recordemos es relativamente reciente, ya que con anterioridad a 2012 la resolución de 20 de diciembre de 2005 no preveía esa potestad-.

Así, debemos reparar en que el art. 10.1 de la Resolución de 28 de diciembre de 2012 es una norma jurídica que reconoce la potestad de que la administración pueda determinar la obligatoriedad de asistencia a una determinada actividad formativa cuando sea necesaria para el buen desempeño de las tareas del puesto de trabajo, pero respecto a esta potestad no se regulan aspectos esenciales, entre ellos la propia competencia para ejercerla. Ni tampoco parece estar libre de discusión que la norma tenga rango suficiente para establecer una atribución válida de la potestad. Se trata de una norma reglamentaria que reconoce a la administración la capacidad para, en ciertos casos, determinar la asistencia obligatoria a una actividad formativa y ello sin que una norma con rango legal - ni la Ley 30/1984 ni el EBEP - prevean la existencia ni extensión de tal potestad. Es por todo ello, por lo que decimos que resulta cuestionable que la Administración pueda determinar para un caso concreto la obligatoriedad de asistir a una actividad formativa exclusivamente con fundamento en el art. 10.1 de la Resolución de 28 de diciembre de 2012.

Cabría preguntarse entonces si el hecho de que determinados empleados públicos no asistan a ciertos cursos formativos de actualización de conocimientos en distintas materias, supondría o no un incumplimiento 
del deber de formación previsto en el art. 54.8 EBEP que pueda acarrear consecuencias jurídicas para los mismos. Como ha argumentado una parte de la doctrina, se podría considerar incluso, que las consecuencias del incumplimiento del deber de formación al que nos hemos referido, acarrearían la apertura de un procedimiento disciplinario contra el empleado infractor de ese deber que no asiste a un curso formativo.

Para llegar a esa conclusión(5) se parte de que ciertamente el art. 52 del EBEP dispone que los principios establecidos en el Capítulo VI del propio Estatuto - entre los que se encuentran los principios de conducta a los que se refiere el antes citado art. 54, en el que se encuadra el deber del empleado de mantener actualizada su formación-, informarán la interpretación y aplicación del régimen disciplinario de los empleados públicos. Se añade a lo anterior que el art. 33 de la Ley de Funcionarios Civiles del Estado - precepto no derogado por el EBEP - dispone que los funcionarios de los cuerpos generales - estamos ante un ámbito de aplicación de alcance más reducido - tienen el deber de asistir a cursos de perfeccionamiento con la periocidad y características que se establezcan por la Presidencia del Gobierno. Lo dicho anteriormente Ilevaría a concluir que en el caso de un funcionario que incumpliese el citado deber de mantener actualizada su formación establecido por el art. 54.8 del EBEP debería considerarse que dicho funcionario está incurriendo en una conducta sancionable, en cuanto ese incumplimiento del deber de formarse constituiría una infracción leve del empleado público en aplicación del art. 8.e RD 33/1986 que establece como faltas leves «el incumplimiento de los deberes y obligaciones del funcionario" y que debe ser interpretado y aplicado de acuerdo con el código de conducta establecido por el EBEP.

En cambio, opinamos que en la realidad práctica la aplicación de dicho planteamiento no resultará pertinente de forma ordinaria. Ello en cuanto, no puede extraerse automáticamente y con carácter general que el hecho de que un funcionario en una situación dada no satisfaga el deber de actualizar su formación en cierta materia, no asistiendo por tanto a un determinado curso formativo; suponga necesariamente un incumplimiento de sus deberes sancionable, y ello porque dado que la conducta no está expresamente tipificada como un supuesto general que produzca responsabilidad disciplinaria - más allá de la tipificación genérica del art. 8.e del RD 33/86- deberá considerarse globalmente y en cada situación las cir-

(5) Para exponer la posibilidad de aplicar ese régimen disciplinario en estos casos concretos, adaptamos el razonamiento que ya se ha desarrollado por otros autores en JIMÉNEZ ASENSIO, Rafael, "La formación de los empleados públicos tras el EBEP ¿Cambio de paradigma?", en Revista Vasca de Administración Pública,n. ${ }^{\circ} 87-88,2010$, pág. 679.

Más tarde se defenderá la dificultad e inadecuación, desde nuestro punto de vista, de acudir de forma general a esa vía disciplinaria, que en realidad debe quedar limitada a supuestos restringidos. 
cunstancias que concurran en la realidad práctica y que sean merecedoras de valoración en cada caso - como por ejemplo, que no se asista a una actividad formativa porque se opte por actualizar por si mismo sus conocimientos ante la falta de posibilidades para asistir a cursos, pudiendo influir en ello las dificultades derivadas de sobrecargas de trabajo relacionadas con la reducción generalizada de personal, dificultades económicas fruto de una, en ocasiones, inadecuada cobertura de los gastos para afrontar los traslados al lugar del curso formativo (6), etc. - . En tales situaciones resultaría complicado aplicar un precepto tan genérico como el art.8.e del RD 33/1986 para sostener que existe una conducta sancionable.

Adicionalmente, puede señalarse que desde el punto de vista gerencial, las técnicas fundamentadas en la coerción, suelen mostrarse mucho menos efectivas que las basadas en fomentar un buen clima laboral, a la hora de garantizar la consecución de los objetivos de la organización, que no son otros que los intereses generales a los que debe orientarse la actuación administrativa conforme al art. 103.1 CE.

Por todo ello, y considerando el alto grado de responsabilidad, profesionalidad y competencia del personal al servicio de las Administraciones Públicas, resulta difícil pensar que el art. 54.8 del EBEP posibilite recurrir de forma generalizada, en los casos en los que el empleado no acuda a un determinado curso formativo, al régimen disciplinario aplicando el art. 8.e del RD 33/1986, sino que más bien dicha consecuencia solo se generaría en situaciones excepcionales marcadas por un notorio incumplimiento de las obligaciones de formación que manifiestamente genere una situación en la que se menoscaben sus responsabilidades con los ciudadanos y los intereses públicos.

En estos últimos casos excepcionales - que son distintos del caso particular de que un funcionario por distintas razones no acuda a un cierto curso formativo (7) - , efectivamente se podrá -y deberá- acudir a la vía disciplinaria con el mayor rigor y es que como bien señala la exposición

(6) Sobre las dificultades económicas que en la práctica pueden desincentivar que los funcionarios asistan a ciertos cursos de formación, conviene tener presente que conforme al art. 7 y el Anexo II del RD 462/2002 que regula las comisiones de servicio, los funcionarios del grupo $\mathrm{C}_{1}$, C2 y E únicamente tienen derecho a una dieta de 28,21 euros brutos diarios para manutención y 48,92 euros diarios para alojamiento. Si se tiene en cuenta que una parte de los cursos formativos se imparten en Madrid, considerando el importe de los conceptos anteriores y el nivel de precios existente, puede concluirse que a la hora de asistir a estas actividades formativas pueden darse situaciones precarias que puedan desincentivar la participación en las mismas.

(7) Se trata de una situación diferente en cuanto aquí existe una transgresión clara de las responsabilidades del funcionario con el ciudadano y con el interés público. Como indicios de esta situación podemos advertir que habitualmente existirá en estos casos una notoriedad en la negativa a formarse por cualquier vía - sea una formación formal o informal, tutelada o individual, rechazando también el autoaprendizaje-, existiendo con frecuencia un "plus de intencionalidad», es decir, un desinterés claro en actualizar sus conocimientos para prestar un servicio público de calidad. 
de motivos del EBEP "la condición de empleado público no sólo comporta derechos, sino también una especial responsabilidad y obligaciones específicas para con los ciudadanos, la propia Administración y las necesidades del servicio". Concluimos así que la vía disciplinaria solo se reservará para esos casos en los que exista una transgresión clara del deber de formación y por tanto de las obligaciones con los ciudadanos y los intereses públicos con una vulneración del código de conducta establecido por el EBEP (8).

Por otra parte, para completar nuestra reflexión jurídica sobre el derecho y el deber a la formación de los empleados públicos, debemos desarrollar la idea de que el deber de mantener actualizada la formación y cualificación contenido en el art.54.8 EBEP está íntimamente relacionado con el propio mandato constitucional previsto en el art. 103.1 CE. Así este precepto constitucional establece -como también hace el artículo 3 de la Ley 40/2015, de Régimen Jurídico de las Administraciones Públicas - que la Administración Pública debe servir con objetividad los intereses generales. Desde esta perspectiva puede decirse que la formación estaría vinculada con el interés público al que se refiere la citada norma constitucional, puesto que cuanto mejor preparados técnicamente estén os empleados públicos, mejor podrán estos gestionar los intereses colectivos y más corresponsables se sentirán de ese interés general (9).

Adicionalmente queremos reparar en la conexión entre el derecho a la formación y el derecho fundamental a la igualdad reconocido en el art. $14 \mathrm{CE}$. Este precepto tendrá manifestaciones directas en la regulación de la formación, pero antes de detallar algunos ejemplos al respecto, queremos incidir en que esa relación entre formación e igualdad no se deriva sólo de la necesidad de hacer efectivo el derecho fundamental que reconoce el art. $14 \mathrm{CE}$ en todas las acciones que realice la Administración, sino también en otros preceptos constitucionales como el art. 23.2 CE que dispone que los ciudadanos " tienen derecho a acceder en condiciones de igualdad a las funciones y cargos públicos». En este punto debe tenerse presente que los principios de igualdad, mérito

(8) La exposición de motivos del EBEP al referirse a este código de conducta regulado en el capítulo VI de la ley, deja claro que el incumplimiento podría tener en algunos casos consecuencias disciplinarias: "Por primera vez se establece en nuestra legislación una regulación general de los deberes básicos de los empleados públicos, fundada en principios éticos y reglas de comportamiento, que constituye un auténtico código de conducta. Estas reglas se incluyen en el Estatuto con finalidad pedagógica y orientadora, pero también como límite de las actividades lícitas, cuya infracción puede tener consecuencias disciplinarias".

(9) SILVA ARDANUY, Francisco Manuel, «Política de formación en las administraciones públicas y programas de detección de necesidades formativas", en Nuevas Políticas Públicas, n. ${ }^{\circ}$ 7, 2011, pág. 49. 
y capacidad en el acceso al empleo público que imponen el art. 23.2 CE y el art. 103.3 CE, deben interpretarse no solo como principios de ingreso a la función pública, sino también como principios rectores a la hora de asignar puestos de trabajo y garantizar la promoción profesional, y ello sin perjuicio de que la intensidad de esos principios tengan un alcance diferente en el ingreso a la función pública y en la carrera administrativa como han señalado la STC 48/1998 y la STS 407/1997, (10).

Remarcamos que los principios de igualdad, mérito y capacidad también rigen en la carrera administrativa y promoción profesional, porque nos interesa destacar que dado que la formación influye significativamente en la promoción profesional, se hace evidente que del art. 23.2 CE también se deriva el deber fundamental de respetar el principio de igualdad en el ámbito formativo. Al art. $14 \mathrm{CE}$ y $23.2 \mathrm{CE}$ se sumarían numerosas normas que conducirían a idéntica conclusión, entre ellas destacamos al menos como normas de referencia lo establecido por el propio art. $1 \mathrm{CE}$-igualdad como valor superior del ordenamiento jurídico- y el art. 9.2 CE - deber de los poderes públicos de promover la igualdad efectiva- (11).

Estas previsiones nucleares de nuestro ordenamiento jurídico justifican y fundamentan la existencia de normativa concreta en materia de formación que trata de garantizar la igualdad en el ámbito formativo. En este sentido destacamos que el art. 60.2 de la Ley Orgánica 3/2007 impone que en materia de formación, con el fin de garantizar el acceso a puestos directivos de las mujeres, el $40 \%$ de las plazas de los cursos deberán reservarse a empleadas públicas. Por otro lado, para que la maternidad no suponga un obstáculo en la promoción profesional y se garantice la actualización de conocimientos, el art. 60.1 de la LO 3/2007 otorga preferencia en el acceso a cursos formativos durante el año siguiente a la reincorporación tras el permiso de maternidad. Idéntica preferencia otorga la misma norma en el acceso a cursos de formación tras disfrutar del permiso de paternidad, lo que sin duda contribuye a promover una distribución más equilibrada entre hombres y mujeres de las responsabilidades familiares.

(10) MESEGUER YEBRA, Joaquín, «El derecho fundamental del art. 23.2 ce al acceso en condiciones de igualdad a las funciones públicas», en Revista Jurídica de Navarra, n. ${ }^{\circ}$ 29, 1999, pág. 273-274.

(11) No es el objeto de este trabajo realizar un estudio en profundidad de las previsiones normativas en materia de igualdad pero conviene destacar que en el ordenamiento comunitario la igualdad también está muy presente. En el derecho originario, se refieren a ella el art. 2 -igualdad como valor de la Unión Europea - y art. 3 -igualdad como objetivo de la Unión Europea- del Tratado de la Unión Europea, así como el art. 8 -obligación de que la Unión se fije como objetivo de todas sus acciones eliminar la desigualdad-, art. 19 - procedimiento legislativo especial para establecer medidas de lucha contra la discriminación-, art. 153 - competencias de apoyo a los Estados en materia de igualdad - o el art. 157 -igualdad retributiva entre hombres y mujeres - del Tratado de Funcionamiento de la Unión Europea. En cuanto a las normas de derecho derivado podemos destacar la directiva 2006/54/UE o en el ámbito de la seguridad social la directiva 79/7/CEE. 
Finalmente resulta oportuno constatar que de acuerdo con el art. 69 EBEP la formación también puede ser definida como uno de los instrumentos de planificación de los recursos humanos. Desde ese punto de vista la formación puede ser estudiada como una herramienta al servicio de la Administración como organización, que puede, como señala el citado precepto, "contribuir a la consecución de la eficacia en la prestación de los servicios y de la eficiencia en la utilización de los recursos económicos disponibles». Dedicaremos el epígrafe siguiente a detallar algunas cuestiones de interés en el estudio de la formación como instrumento al servicio de las organizaciones públicas.

\section{La formación desde el punto de vista organizacional. El carácter estratégico de la formación. La formación en competencias y la formación ética como complemento necesario de la formación técnica. Los cauces para la virtualidad de la formación: la formación presencial frente al e-learning y la formación activa frente a la formación pasiva}

La formación ha llegado a ser definida como «el cambio planificado para adquisición, retención y transferencia de conocimientos y destrezas necesarios para el eficaz desempeño de las tareas de un puesto de trabajo" (12). Se trata de una definición que deja patente el carácter estratégico de la formación para la Administración como organización(13). En este sentido debe tenerse presente que la formación contribuye a la promoción profesional y el acceso a nuevos puestos de trabajo, dejando vacantes los anteriores, tratándose por tanto de un instrumento estratégico relacionado con la planificación de los recursos humanos de la Administración - no en vano el art. 69 del EBEP, referido a los instrumentos de planificación en materia de recursos humanos hace referencia, dentro de ellos, a la formación-. Para ilustrar el carácter estratégico de la formación se ha señalado que «El diseño de los cursos formativos y su gestión en el tiempo (cuándo ofertar qué formación) es una herramienta estratégica de intervención ya que la superación de procesos formativos, en teoría, debe proveer puestos en carrera. Este hecho debe estar planificado ya que su primera consecuencia es la movilidad del personal y la consi-

(12) GORRITI BONTIGUI, Mikel, "Un sistema de reforma del empleo público alternativo a los recortes de personal», en Revista Vasca de Gestión de Personas y Organizaciones Públicas, n. ${ }^{\circ} 4,2013$, pág. 20.

(13) Dado el carácter estratégico de la formación, insistiremos más abajo en la exigencia de que la formación debe estar vinculada, no solo a las preferencias de los trabajadores sino también a las necesidades de la organización. 
guiente generación de vacantes. La formación y las jubilaciones son quienes generan las vacantes en las AAPP que a su vez son condición para poder aplicar una planificación de RRHH acorde con el diseño organizativo estratégico.» (14)

Queremos insistir en la idea de que solo con una planificación anticipada de la formación y coherente con la dirección hacia dónde quiere dirigirse la organización, con los cambios en el entorno y con los objetivos de la administración, será posible garantizar la máxima eficacia en el desempeño de las funciones de los recursos humanos de la administración a través de cuya actuación podrán alcanzarse los objetivos públicos. Por otro lado es importante que reseñemos que para asegurar una gestión eficaz y el óptimo cumplimiento de los objetivos de la organización, existe una necesidad de que la formación promueva, no solo la actualización normativa y los conocimientos técnicos especializados sino también competencias como la adaptación al entorno, a la tecnología, el trabajo en equipo, la motivación, así como la orientación a resultados del personal y como no, las habilidades directivas de los empleados públicos que desempeñan puestos de mayor responsabilidad (15).

De hecho, para el caso de los directivos públicos, si se produjesen cambios legislativos que lo hiciesen posible - entre ellos debe llevarse a cabo la aprobación del estatuto del directivo público - podría, dada la especial necesidad de garantizar unas adecuadas competencias en este tipo de personal, hacerse obligatorio que para el acceso a puestos de dirección fuera necesario la previa realización de un programa de formación en habilidades directivas (16).

Otra cuestión trascendental en materia de formación desde el punto de vista organizacional es la relativa a garantizar una adecuada evaluación de la formación y control de los formadores -que garantice la cali-

(14) GORRITI BONTIGUI, Mikel, "Un sistema de reforma del empleo público alternativo a los recortes de personal», en Revista Vasca de Gestión de Personas y Organizaciones Públicas, n. ${ }^{\circ} 4,2013$, pág. 21.

(15) La necesidad de formación en estas materias es señalada en distintos trabajos académicos, entre ellos:YERGA COBOS, Alfonso., "La formación y los empleados públicos: ¿para qué y en qué?", en Nuevas Políticas Públicas, n. ${ }^{\circ} 7,2011$, pág. 24. También se consideran como materias imprescindibles la comunicación, trabajo en equipo, motivación, planificación y organización en LÓPEZ MARTíNEZ, Pedro Ángel, Modelo de formación por competencias para jefes y directivos de la administración pública española (tesis doctoral). UIB, Mallorca, 2016, pág. 225.

(16) En países vecinos como es el caso de Portugal, las políticas públicas de formación también han pretendido fomentar capacidades para conducir procesos de cambio, dirigir personas, desarrollar competencias orientadas al logro de los objetivos... llegándose a haber valorado incluso la posibilidad que la superación de un curso formativo centrado en tales aspectos, el denominado CEAGP - programa de acceso al servicio público, por sus siglas en portugués - llegase a establecerse como requisito de acceso a los puestos directivos, VALADARES TAVARES, Luis, "Un nuevo modelo de formación para directivos de la administración pública portuguesa», en Revista de Administración Pública, n. ${ }^{\circ} 110,2004$, pág. 54. 
dad de la misma - así como un adecuado diagnóstico de las necesidades de la organización - habida cuenta del carácter estratégico de la formación y su impacto en la planificación de recursos humanos-(17). Respecto a ese diagnóstico de las necesidades, es importante que la formación no esté determinada solo por las preferencias individuales del trabajador sino también y especialmente por las necesidades estratégicas de la organización, y ello con aún mayor exigencia cuando se trata de directivos públicos(18). Lo anterior es relevante, ya que algunos estudios muestran que los directivos públicos mantienen una preferencia por la formación tradicional de tipo técnico frente a la formación gerencial o por competencias. (19) Ello refuerza la necesidad, que hemos referido previamente, de potenciar e incentivar la formación en materias como las habilidades directivas, gestión del cambio, comunicación, u orientación a resultados.

Por el contrario, no queremos decir con todo ello que la formación deba estar orientada exclusivamente a lograr una gestión eficaz y eficiente. La Administración pública, no es - ni debe ser - una empresa privada y por tanto sus políticas en materia de personal, incluyendo la formación, deben estar orientadas no sólo a la eficiencia, sino que también deben estar muy orientadas al logro y efectividad de unos valores democráticos y de servicio al interés general. Esta posición también es mantenida por otros autores, que advierten de la necesidad de corregir las tensiones que se pueden producir entre los valores asociados al mercado y al interés general. Se señala que el aumento en el sector público de la preponderancia de valores asociados al mercado y la empresa, que no siempre son compatibles con las necesarias garantías que aseguren el control legal y el servicio al interés general, puede generar fricciones, debiendo la formación contribuir a resolver esas contradicciones(20). Se

(17) Ambos son recogidos como puntos críticos en LÓPEZ MARTíNEZ, Pedro Ángel., Modelo de formación por competencias para jefes y directivos de la administración pública española (tesis doctoral). UIB, Mallorca, 2016, pág. 229.

(18) Volviendo al caso de Portugal, se ha sugerido que precisamente los principales problemas de la formación en la Administración Pública portuguesa son la falta de una correcta evaluación de la formación y un adecuado diagnóstico de las necesidades. En tal sentido se señala que la formación ha estado más condicionada por esas preferencias individuales del trabajador que por las necesidades estratégicas organizacionales. MADUREIRA, César, "La formación comportamental de los directivos superiores en la administración pública portuguesa», en Revista Europea de Formación Profesional n. ${ }^{\circ} 39,2006$, pág. 62 . Esa falta de orientación de la formación a las necesidades de organización ha sido común también en otros países iberoamericanos tal y como se recoge en LONGO, Francisco y IACOVIELLO, Mercedes, "Hacia un empleo público más profesional en Centroamérica», en Revista del CLAD Reforma y Democracia, n. ${ }^{\circ}$ 56, 2013, págs. 1-17.

(19) LÓPEZ MARTíNEZ, Pedro Ángel, Modelo de formación por competencias para jefes y directivos de la administración pública española (tesis doctoral). UIB, 2016, pág. 208.

(20) VEIRA VEIRA, José Luis, "Cambio cultural y formación en las organizaciones públicas», en $R e$ vista Española de Investigaciones Sociólogicas, n. ${ }^{\circ}$ 77-78,1997, pág. 213. 
concluye desde esta posición que la formación no puede estar vinculada únicamente a la eficiencia sino que sin renunciar al objetivo de ayudar a asegurar una buena -y económica - gestión de los servicios públicos, la formación también debe contribuir al aseguramiento de una ética democrática y de servicio a la comunidad, que debe integrarse en la cultura organizativa de la administración pública.

Es por ello por lo que la política de formación, debe también incluir en su contenido acciones formativas referidas a normas de comportamiento y valores éticos - que bien podrían proponerse en un futuro como obligatorias, especialmente en el caso de los directivos públicos - destinadas a garantizar el sometimiento a los intereses generales y la integridad en el sector público, sirviendo además como acción preventiva frente a la corrupción(21). La doctrina viene defendiendo que la formación debe promover entre los empleados públicos valores éticos que garanticen una conducta inspirada por la igualdad de trato e independencia, alejada de ciertos rasgos presentes en nuestra sociedad como el amiguismo, las influencias y las recomendaciones, potenciando así una formación deontológica y en normas éticas que inculque valores asociados a la integridad (22).

Dicho lo anterior, concluimos, respecto al contenido de la formación de los empleados públicos, que esta debe incidir en principios y valores éticos, sirviendo como hoja de ruta los previstos en el art. 52 del EBEP. Las acciones formativas deben promover por tanto los principios de «objetividad, integridad, neutralidad, responsabilidad, imparcialidad, confidencialidad, dedicación al servicio público, transparencia, ejemplaridad, austeridad, accesibilidad, eficacia, honradez, promoción del entorno cultural y medioambiental, y respeto a la igualdad entre mujeres y hombres» que deberían ser asumidos por todos los empleados públicos.

Para finalizar, tras haber desarrollado la idea de que la formación debe centrarse no solo en contenidos de tipo técnico, sino también en competencias y por supuesto en valores y normas éticas, solo nos resta plantear cuál debería ser el cauce a través del cual se instrumente dicha formación. Sobre esta cuestión solo pretendemos dejar esbozadas unas ideas fundamentales.

En primer lugar, no se nos puede escapar que el desarrollo de las tecnologías de la información abre nuevas posibilidades a la hora de de-

(21) Es la posición defendida en uno de los trabajos de Villoria Mendieta y Moreno Tejada, quienes llegan a señalar que la formación es «uno de los pilares fundamentales de toda estrategia que pretenda prevenir la corrupción y mejorar la integridad es el sector público». VILLORIA MENDIETA, Manuel y MORENO DE TEJADA, Alberto, "La formación en ética en la administración pública: un análisis comparado", en Nuevas Políticas Públicas, n. ${ }^{\circ}$ 7, 2011, págs. 108-110.

(22) BELTRÁN VILLALBA, Miguel, "La formación y los empleados públicos», en Revista Española de Investigaciones Sociólogicas, n. ${ }^{\circ} 77-78,1997$, págs. 60-64. 
sarrollar la formación de los empleados públicos. Surge así la opción de instrumentar la formación a través del denominado e-learning, que por sus propias características permite formar simultáneamente a un mayor número de empleados públicos, con menores costes y con mayor flexibilidad. Si bien, algunos estudios comparativos entre el e-learning y la formación presencial, sugieren que la primera no es más eficaz que la presencial, obteniendo el e-learning resultados ligeramente inferiores en variables como la satisfacción con la formación, la orientación a las necesidades específicas del puesto de trabajo o la motivación (23).

Así, respecto a esta primera cuestión concluimos que, sin minusvalorar las opciones que ofrece el e-learning para dar respuesta a necesidades formativas a las que anteriormente no se podía hacer frente, no resultaría oportuno desplazar la formación presencial en favor de la formación online a distancia, puesto que la formación presencial ha dado resultados acreditados y permite además incorporar con mayor facilidad nuevas metodologías de aprendizaje más activas y participativas - a la que nos referiremos a continuación-. Además, entre las ventajas que desaconsejan el abandono de la formación presencial en favor de la online, se incluye también la relativo a su capacidad para relacionar a personal de distintas unidades funcionales $-e$ incluso de distintas regionescontribuyendo al establecimiento de redes de colaboración y a la consolidación de la cultura organizativa.

Como línea adicional que dejamos abierta para futuros estudios, podría resultar interesante estudiar las posibles ventajas que podrían lograrse con la implantación de una tercera clase de acciones formativas de tipo blended learning, es decir combinando el aprendizaje online con las acciones formativas presenciales, lo que quizá permitiría combinar la flexibilidad del autoaprendizaje online y la mayor facilidad para la participación activa y la interacción del aprendizaje presencial (24).

Vistos los distintos cauces a través de los cuales puede instrumentarse la formación de los empleados públicos (presencial, e-learning, o blen$d e d)$, resulta oportuno que finalicemos haciendo mención a la metodología de ese aprendizaje. Frente al aprendizaje tradicional, basado en la unidireccionalidad profesor-alumno y el enfoque teórico de las clases magistrales, es habitual que se vaya abriendo paso la utilización de métodos que se basan en el estudio y resolución casos prácticos o en la reali-

(23) QUESADA PALLARES, Carla, ESPONA BARCONS, Berta, CIRASO CALÍ, Anna y PINEDA HERRERO, Pilar, "La eficacia de la formación de los trabajadores de la administración pública española: comparando la formación presencial con el eLearning", en Revista del CLAD Reforma y Democracia, n. ${ }^{\circ} 61,2015$, pág. 120.

(24) Esta metodología mixta es propuesta en VARELA ÁLVAREZ, E. J., "¿Cómo dirigir un curso de directivos públicos?: entre el entrenamiento de gestores y la formación de líderes institucionales", Nuevas Políticas Públicas, n. ${ }^{\circ}$ 7, 2011, p.39. 
zación de talleres (25). Es por ello, por lo que como perspectivas de futuro para la formación en la Administración pública, concluimos que la incorporación de este tipo de metodología más práctica y activa parece recomendable - siempre con cautela y sin renunciar a las fortalezas que también ha demostrado la formación tradicional-.

En el horizonte existen incluso otras innovaciones en el ámbito de la formación a las que la Administración deberá estar muy atenta. Se trata de enfoques que proponen una metodología de aprendizaje colaborativo y social que comparta el conocimiento personal con el conocimiento institucional y social y con un mayor protagonismo y un papel más activo de los empleados públicos así como una mayor colaboración entre ellos en el propio proceso aprendizaje(26).

\section{Reflexiones finales}

Hemos advertido que la formación es un importante instrumento de planificación de los recursos humanos al servicio de la Administración Pública. Se trata de un instrumento que está llamado a adquirir una especial relevancia si tenemos en cuenta que las Administraciones deben enfrentarse a unas demandas crecientes y ello en un contexto adverso de reducción de efectivos derivado de las políticas de adelgazamiento de la Administración - tal y como ha ocurrido también en la organización a la que pertenezco, la Administración de la Seguridad Social, que con un una plantilla un $12,7 \%$ inferior a la de hace cinco años (27) ha tenido la responsabilidad de gestionar un número de pensiones un 5,2\% mayor y de aumentar la recaudación un $16 \%(28)-$. En ese contexto de escasez de recursos humanos, una correcta política de planificación de los mismos,

(25) En el caso de la formación de directivos, algunos estudios muestran que la utilización de este tipo de metodologías es mejor valorada por los usuarios de los cursos formativos, LÓPEZ MARTíNEZ, Pedro Ángel., Modelo de formación por competencias para jefes y directivos de la administración pública española (tesis doctoral). UIB, Mallorca, 2016, pág. 226.

(26) Es la línea defendida por Martínez Marín en su obra MARTíNEZ MARíN, Jesús, Nuevos modelos de formación para empleados públicos. Guía para la transformación. Editorial UOC, Barcelona, 2016.

(27) Datos extraídos del estudio de personal de la seguridad social realizado por CCOO y disponible en: http://www2.fsc.ccoo.es/webfscmadrid/Sectores:Administracion_General_del_ Estado:Actualidad:1016158--CCOO_sigue_denunciando_la_constante_perdida_de_personal_en_la_ Seguridad_Social (última consulta 10 de Septiembre de 2017).

(28) Fuente: Seguridad Social. Datos sobre número de pensiones disponibles en: http://www.seg social.es/Internet_1/Estadistica/Est/Pensiones_y_pensionistas/Series_de_Pensiones_en_vigor_y_Pensionistas/ESTC 005257 (última consulta 10 de Septiembre de 2017). Datos consolidados sobre recaudación por cotizaciones 2012 a 2016 disponibles en: http://www.seg-social.es/Internet_1/Estadistica/Est/Presupuesto_aprobado/Ingresos/174952 (última consulta 10 de Septiembre de 2017). 
resulta si cabe, aún más importante. Es por ello por lo que reviste un especial interés estimular el debate sobre qué dirección debe tomar la formación de los empleados públicos como instrumento al servicio de los intereses y objetivos de la organización pública.

Por otro lado, respecto a la formación desde la perspectiva netamente jurídica, queremos hacer notar, que no tiene por qué tratarse de una perspectiva necesariamente alejada de la perspectiva organizacional. Así desde el punto de vista organizacional hemos defendido la necesidad de realizar una planificación estratégica de forma anticipada y de orientar la formación no solo a la adquisición de conocimientos de tipo técnico sino también al desarrollo de competencias como la adaptación al entorno, a la tecnología, el trabajo en equipo, la motivación, o la orientación a resultados; todo ello como garantía para el logro de los objetivos de la organización, esto es el interés general. Es decir, lo que se estaría proponiendo desde el punto de vista organizacional es precisamente aquello que desde la perspectiva jurídica recalcamos que el art. 103.1 CE mandata: una Administración que sirva con objetividad y eficacia los intereses generales. Igualmente, desde el punto de vista organizacional hemos recomendado potenciar la formación en ética como instrumento para garantizar la integridad de la organización y en realidad esto pasa precisamente por reforzar y hacer efectivos los valores a los que se refieren los arts. 52 a 54 del EBEP, incluyendo entre ellos valores como la igualdad, materia en la que hemos puesto especial énfasis al final de nuestra reflexión jurídica. Ello muestra que, como decíamos al principio de nuestro trabajo, la perspectiva jurídica de la formación no tiene por qué ser necesariamente antagónica con la perspectiva organizacional de la misma.

Finalmente queremos terminar estas páginas reproduciendo, a modo de deseo para el futuro, un elocuente principio que hemos encontrado recogido ilustrado en otro trabajo académico. Se trata de la máxima de "formar hoy para no subcontratar o externalizar en el futuro" (29). Que así sea.

\section{Bibliografía}

BELTRÁN VILLALBA, Miguel, "La formación y los empleados públicos», en Revista Española de Investigaciones Sociólogicas, n. ${ }^{\circ}$ 77-78,1997, págs. 51-68.

(29) SÁNCHEZ-SAUS LASERNA, Marta y SILVA ARDANUY, Francisco Manuel, «Formación de empleados públicos, desempeño y empleabilidad ante la racionalización de la Administración Pública", en Nuevas Políticas Públicas, n. ${ }^{\circ}$ 7, 2011, pág. 74. 
GORRITI BONTIGUI, Mikel, "Un sistema de reforma del empleo público alternativo a los recortes de personal", en Revista Vasca de Gestión de Personas y Organizaciones Públicas, n. ${ }^{\circ} 4,2013$, págs. 8-23.

JIMÉNEZ ASENSIO, Rafael, "La formación de los empleados públicos tras el EBEP ¿Cambio de paradigma?», en Revista Vasca de Administración Pública, n. ${ }^{\circ} 87-88,2010$, págs. 637-688.

LONGO, Francisco y IACOVIELLO, Mercedes, "Hacia un empleo público más profesional en Centroamérica», en Revista del CLAD Reforma y Democracia, n. ${ }^{\circ}$ 56, 2013, págs. 1-17.

LÓPEZ MARTíNEZ, Pedro Ángel, Modelo de formación por competencias para jefes $y$ directivos de la administración pública española (tesis doctoral), UIB, Mallorca, 2016

MADUREIRA, César, "La formación comportamental de los directivos superiores en la administración pública portuguesa», en Revista Europea de Formación Profesional, n. ${ }^{\circ}$ 39, 2006, págs. 50-65.

MARTÍNEZ MARÍN, Jesús, Nuevos modelos de formación para empleados públicos. Guía para la transformación. Editorial UOC, Barcelona, 2016.

MESEGUER YEBRA, Joaquín, «El derecho fundamental del art. 23.2 ce al acceso en condiciones de igualdad a las funciones públicas", en Revista Jurídica de Navarra, n. ${ }^{\circ} 29,1999$, págs. 261-281

RIVERO LAMAS, Juan, «EI proceso de laboralización de la función pública: aspectos críticos y límites", en Anuario Jurídico de la Rioja, n. ${ }^{\circ} 2,1996$, págs. 79-132

SILVA ARDANUY, Francisco Manuel, "Política de formación en las administraciones públicas y programas de detección de necesidades formativas", en Nuevas Políticas Públicas, n. ${ }^{\circ}$ 7, 2011, págs. 45-59.

SÁNCHEZ-SAUS LASERNA, Marta y SILVA ARDANUY, Francisco Manuel., "Formación de empleados públicos, desempeño y empleabilidad ante la racionalización de la Administración Pública», en Nuevas Políticas Públicas, n. ${ }^{\circ} 7,2011$, págs. 45-59.

QUESADA PALLARES, Carla, ESPONA BARCONS, Berta, CIRASO CALÍ, Anna y PINEDA HERRERO, Pilar, "La eficacia de la formación de los trabajadores de la administración pública española: comparando la formación presencial con el eLearning", en Revista del CLAD Reforma y Democracia, n. ${ }^{\circ} 61,2015$, págs. 107-132.

VALADARESTAVARES, Luis, "Un nuevo modelo de formación para directivos de la administración pública portuguesa», en Revista de Administración Pública, n. ${ }^{\circ} 110,2004$, págs. 53-56.

VARELA ÁLVAREZ, Enrique José, "¿Cómo dirigir un curso de directivos públicos?: entre el entrenamiento de gestores y la formación de líderes institucionales", en Nuevas Políticas Públicas, n. ${ }^{\circ}$ 7, 2011, pág. 27-42. 
VEIRA VEIRA, José Luis, "Cambio cultural y formación en las organizaciones públicas", en Revista Española de Investigaciones Sociólogicas, n. ${ }^{\circ}$ 77-78,1997, págs. 199-216.

VILLORIA MENDIETA, Manuel y MORENO DETEJADA, Alberto, «La formación en ética en la administración pública: un análisis comparado», en Nuevas Políticas Públicas, n. ${ }^{\circ} 7,2011$, págs. 93-111.

YERGA COBOS, Alfonso, "La formación y los empleados públicos: ¿para qué y en qué?», en Nuevas Políticas Públicas, n. ${ }^{\circ} 7,2011$, págs. 11-25.

Trabajo recibido el 10 de septiembre de 2017

Aceptado por el Consejo de Redacción el 20 de octubre de 2017 
LABURPENA: Administrazio Publikoen zerbitzura lan egiten duten enplegatuen prestakuntza ikuspuntu juridikotik aztertu daiteke -langilearen eskubidea eta betebeharra den aldetik-, bai eta erakunde-ikuspegitik ere - erakundeko helburuen arabera prestakuntza ezartzeko modurik onena zehazteko ikuspegian oinarrituta-. Ikuspegi juridikoan, zehazki, prestakuntza jasotzeko betebeharra urratzeak dakartzan ondorioak aztertuko ditugu. Halaber, berariaz ikertuko dugu prestakuntzaren eta berdintasunerako eskubidearen arteko harremana, bai eta administrazioak interes orokorra lortzeko duen betebeharrarekiko lotura ere. Azken alderdi horrek, hain zuzen ere, erakunde-ikuspegiarekin egingo du bat. Horren barruan aztertuko ditugu, besteak beste, planifikazio estrategikoa aldez aurretik egiteko beharrizana, eta prestakuntza, ezagutza teknikoak eskuratzera ez ezik, beste era bateko eskumenak garatzera bideratzeko beharrizana; hori guztia, interes orokorra lortzen dela bermatzeko.

GAKO HITZAK: Prestakuntza. Enplegatu publikoak. Administrazio publikoa.

RESUMEN: La formación de los empleados al servicio de las Administraciones Públicas puede analizarse desde un punto de vista jurídico - como derecho y deber del empleado - y desde una perspectiva organizacional -óptica basada en determinar el mejor modo de configurar la formación con arreglo a los objetivos de la organización-. Respecto a la perspectiva jurídica, estudiaremos las consecuencias del incumplimiento del deber de formarse, analizando igualmente la relación existente entre la formación y el derecho a la igualdad, así como su conexión con el deber administrativo de perseguir el interés general. Esto último enlazará con el punto de vista organizacional donde recogeremos, entre otros extremos, la necesidad de realizar una planificación estratégica de forma anticipada y de orientar la formación no solo a la adquisición de conocimientos de tipo técnico sino también al desarrollo de competencias de otra índole; todo ello como garantía para el logro del propio interés general.

PALABRAS CLAVE: Formación. Empleados públicos. Administración pública.

ABSTRACT: The training of Public Administration employees can be analyzed from a legal point of view - as a right and duty for the employee- or from an organizational perspective - from an optic based in determining the best way to configure the training in accordance with the objectives of the organization-. With regard to the legal perspective, we will study the consequences of infringement of the duty of training, also examining the relationship between training and right to equality, together with its connection to the administrative duty to pursue the general interest. This latter will link with the organizational point of view where we will reveal, amongst other things, the need for establishing an anticipated strategic planning and for targeting the training not only to to acquire technical knowledge but also to develop competences of a different type; all as a guarantee for achieving the general interest.

KEYWORDS: Training. Public employees. Public Administration. 